\title{
NEUROCIENCIAS EN LA JUNTA PARA AMPLIACIÓN DE ESTUDIOS
}

\author{
Alfredo Baratas Díaz \\ Dpto. Biología Celular. Facultad de Ciencias Biológicas. Universidad Complutense de Madrid
}

\section{RESUMEN}

El desarrollo de las Neurociencias en la España del primer tercio del siglo XX tuvo un fuerte componente histológico y patológico. La obra de Santiago Ramón y Cajal y de Luis Simarro se continuó en la labor investigadora de algunos discípulos relevantes: Nicolás Achúcarro, Gonzalo Rodríguez Lafora, Fernando de Castro, etc. Algunos de ellos tuvieron que compatibilizar ocupaciones diversas, incluso el ejercicio profesional de la psiquiatría, antes de obtener un modesto - pero estable - puesto de investigación. A pesar de algunos desajustes en el desarrollo institucional de los centros y los avatares biográficos personales, la Junta para Ampliación de Estudios se constituyó en en la gran institución que amparó la formación internacional de los investigadores y les dotó de un marco en que desarrollar su trabajo.

PALABRAS CLAVE: Neurohistología, Psiquiatría, España, Junta para Ampliación de Estudios.

\section{NEUROSCIENCE IN THE JUNTA PARA AMPLIACIÓN DE ESTUDIOS}

\section{ABSTRACT}

The development of the Neurociencias in the Spain at the first third of 20 th century had a strong histological and pathological component. The work of Santiago Ramon and Cajal and Luis Simarro was continued by some excellent disciples: Nicolas Achúcarro, Gonzalo Rodriguez Lafora, Fernando de Castro, etc. Some of them had to make compatible diverse occupations, even the professional exercise of psychiatry, before obtaining a modest — but stable - position of investigation. In spite of some misalignments in the institutional development of the centers and the personal biographical ups and downs, the Junta para Ampliación de Estudios was the great institution that fomented the international formation of the investigators and equiped to them with the means to develop its work

KEY WORDS: Neurohistology, Psychiatry, Spain, Junta para Ampliación de Estudios. 


\section{INTRODUCCIÓN}

Las Neurociencias fueron una de las disciplinas biológicas más favorecidas por la actividad de la Junta para Ampliación de Estudios; analizar su desarrollo permite ejemplificar los grandes aciertos del sistema de política científica que representó esta institución y apuntar algunas de las lagunas y carencias, que también las hubo, en el proceso de consolidación. Las Neurociencias españolas en el primer tercio del siglo XX tuvieron su centro de gravedad en la Neurohistología, disciplina que contaba con notables especialistas desde las décadas finales del siglo XIX; la actividad de la Junta permitió una progresiva diversificación temática que, partiendo de la Histología más clásica, evolucionó hacia otros enfoques.

CAJAL: PIEDRA MILIAR DE LA INVESTIGACIÓN NEURO-HISTOLÓGICA DEL SIGLO XIX.

La figura más notable de la investigación neurobiológica española es, sin duda, Santiago Ramón y Cajal (1852-1934). Su inclinación hacia la investigación se remonta a los últimos años de la década de 1870, cuando — siendo profesor auxiliar de Anatomía en la Facultad de Medicina de la Universidad de Zaragoza - viajó a Madrid para realizar el doctorado y trabó contacto con Aureliano Maestre San Juan (1828-1890), catedrático de Histología en la Facultad madrileña.

\footnotetext{
«Sugestionado por algunas bellas preparaciones micrográficas que el doctor Maestre de San Juan y sus ayudantes (el doctor López García entre otros) tuvieron la bondad de mostrarme, y deseoso, por otra parte, de aprender lo mejor posible la Anatomía general, complemento de la descriptiva, resolví, a mi regreso a Zaragoza, crearme un Laboratorio micrográfico» ${ }^{1}$.
}

Dos aspectos, mencionados en la cita previa, merecen una pequeña digresión: en primer lugar la fascinación que ejercían sobre Cajal las imágenes de valor estético, la inclinación artística que subyacía en él desde niño; en segundo lugar, la disposición a asumir esfuerzos personales -en ocasiones onerosos - en aras de su formación e investigación; cuando afirma su resolución a crear un laboratorio, está asumiendo un coste económico considerable

1 RAMÓn y CAJAL, S. (1976), Mi infancia y juventud, Madrid, Espasa Calpe, p. 245. 
y evidencia una constancia, casi tozudez, que le permite superar por el ánimo de su voluntad cualquier limitación externa.

Establecido el laboratorio, comprados los reactivos, los primeros libros y revistas y adquirido - a plazos - el primer microscopio, nuestro protagonista empezó "a trabajar en la soledad, sin maestros, y con no muy sobrados medios; más a todo suplía mi ingenuo entusiasmo y mi fuerza de voluntad. Lo esencial para mi era modelar mi cerebro, reorganizarlo con vistas a la especialización, adaptarlo en fin, rigurosamente a las tareas del Laboratorio» ${ }^{2}$. Afirma Cajal que en un primer momento se limitó a curiosear sin método (sic); pero esta etapa duró poco y rápidamente (1880) pudo dar a la imprenta un primer trabajo científico con el título Investigaciones experimentales sobre la inflamación en el mesenterio, la cortea y el cartílago, tema sobre el que había versado - en un tono muy general y poco o nada original- su tesis doctoral. Un año después publicó Observaciones microscópicas sobre las terminaciones nerviosas en los músculos voluntarios ${ }^{3}$. El autor consideró estos trabajos como mediocres, pero afirmó que le confirieron destreza con los métodos histológicos, le habituaron a la larga y metódica observación microscópica y le dotaron de un sano escepticismo, que le permitiría «flexibilidad para cambiar bruscamente de opinión y corregir errores y ligerezas» ${ }^{4}$.

En 1883 Cajal obtuvo, por oposición, la cátedra de Anatomía de la Facultad de Medicina de la Universidad de Valencia, lo que permitió su estabilidad profesional definitiva y supuso el aldabonazo para su carrera investigadora. La Universidad valenciana era más rica -intelectualmente y científicamente- que la aragonesa, y allí entró Cajal en contacto con nuevos compañeros y nuevos retos científicos. Tras un breve contacto con la Bacteriología, que cristalizaba algunos intereses previos del investigador y acuciado por el súbito brote de una epidemia de cólera, Cajal enfocó sus intereses científicos en la Histología y comenzó (1884) la edición de un Manual de Histología Normal y Técnica Micrográfica. Este texto es significativo ya que exigía un trabajo de sistematización de las observaciones microscópicas, las técnicas de tinción, etc.; cuando el libro se completó en 1889 — se editaba por entregas - supuso un volumen novedoso en nuestro panorama científico, ya que estaba basado

2 Ibidem, p. 247.

3 Los trabajos de esta etapa de iniciación en la actividad investigadora han sido reproducidos en: RAMÓN Y CAJAL, S. (2001), Discurso de doctorado y trabajos de juventud, Madrid, CEES - Ediciones Universidad Europea, en edición a cargo de Ángel Merchán Pérez.

4 RAMÓn y CAJAL, S. (1917), Recuerdos de mi vida: Historia de mi labor científica, Madrid, Imprenta y Librería de Nicolás Moya. p. 32. 
en observaciones propias y no era una mera traducción de textos foráneos. Paralelamente, continuó publicando aportaciones puntuales sobre la estructura del cristalino, fibras musculares, cartílago, etc; estos trabajos fueron editados como breves avances de investigación, en castellano, y tuvieron, además, una versión ampliada - en francés - que se publicaron en revistas internacionales.

Por tanto, a finales de la década de 1880 — tras casi diez años de trabajoCajal era un profesor universitario de trayectoria y vocación clara: con una sólida formación anatómica e histológica, había ya realizado aportaciones científicas con cierta repercusión en medios nacionales e internacionales.

\section{LA IMPREGNACIÓN DE GOLGI Y LA VOCACIÓN NEUROHISTOLÓGICA}

En 1887 Cajal viajó a Madrid como miembro de un tribunal de oposición y durante su estancia visitó - nuevamente- el laboratorio de Maestre, más el Museo de Ciencias Naturales y diversos laboratorios personales, entre ellos el de Luis Simarro (1851-1921). Fue éste quién le enseñó por vez primera preparaciones realizadas con el método del italiano Camilo Golgi (1843-1926), que permitía la formación de un depósito de sales de plata sobre la superficie de algunas células nerviosas y mostraba hasta los últimos extremos de las pocas células impregnadas. La descripción original del procedimiento era vaga e imprecisa y Cajal afirma:

\footnotetext{
«A mi regreso a Valencia decidí emplear en grande escala el método de Golgi y estudiarlo con todo el tesón de que soy capaz. Innumerables probaturas /.../ en muchos centros nerviosos y especies animales, nos convencieron de que el nuevo recurso analítico tenía ante sí brillante porvenir, sobre todo si se encontraba manera de corregirlo de su carácter un tanto caprichoso y aleatorio. /.../ De cualquier modo, estábamos ya en posesión del instrumento requerido. Faltaba solamente determinar escrupulosamente las condiciones de la reacción cromo-argéntica, disciplinarla para adaptarla a cada caso particular» ${ }^{5}$.
}

Cajal, que durante diez años se había formado como histólogo general y estaba dotado de la meticulosidad y paciencia suficiente, fue capaz de sistematizar la veleidosa técnica de Golgi especificando tiempos, proporciones de reactivos y fijadores para distintas porciones de tejido nervioso. Pero, además, planteó una estrategia de investigación notable, a la que denominó método ontogénico, que explicó perfectamente en su autobiografía científica:

5 RAMÓN Y CAJAL (1917), p. 76-77. 


\section{NEUROCIENCIAS EN LA JUNTA PARA AMPLIACIÓN DE ESTUDIOS}

«Y si el encéfalo y demás órganos centrales adultos del hombre y vertebrados son demasiado complejos para permitir escrutar, mediante dicho recurso, su plan estructural, ¿por qué no aplicar sistemáticamente el método a los animales inferiores o a las fases tempranas de la evolución ontogénica, en las cuales el sistema nervioso debe ofrecer organización sencilla y, por decirlo así, esquemática?» ${ }^{6}$.

Con ambas herramientas (una técnica histológica sistematizada y una estrategia de investigación) entre 1888, fecha en que publica el trabajo Estructura de los centros nerviosos de las aves, y 1892 sentó las bases de la Neurohistología moderna y, en la medida que sus interpretaciones anatómicas y funcionales eran exactas, la obra de Cajal representa el punto de arranque para la Neurobiología contemporánea.

No es este el marco para detallar las aportaciones cajalianas ${ }^{7}$ en las dos últimas décadas del siglo XIX, pero es posible destacar los cuatro grandes ejes sobre las que se vertebra:

1. Demostración de la teoría neuronal: el tejido nervioso está constituido por células independientes (neuronas) y la transmisión del estímulo nervioso se hace por contacto entre ellas y no - como creían los reticularistas - por fusión de las prolongaciones nerviosas.

2. Deducción de la «polarización dinámica» de las neuronas, en la que atribuye a las dendritas la recepción del estímulo nervioso y al axón la distribución del mismo a las células cercanas. De este principio de polarización se deduce la posibilidad de trazar las vías o caminos que sigue el estímulo nervioso a lo largo de los centros nerviosos.

3. El estudio anatómico de los centros nerviosos (retina, cerebelo, médula, corteza cerebral, etc) en los distintos grupos animales (con especial énfasis en los vertebrados), identificando los tipos celulares que los componen, su disposición en capas, la interrelación entre ellos, sus modificaciones a lo largo de la escala animal, etc.

4. Descripción de los procesos relacionados con el crecimiento de las prolongaciones de las células nerviosas y la formulación de hipótesis científicas para explicarlo (hipótesis neurotrópica).

6 RAMÓN Y CAJAL (1917), p. 79.

7 Véase el capítulo 6 de Baratas Díaz, A (2006). Ramón y Cajal, Madrid, Nívola Libros y el trabajo: BARATAS DíAZ, A. (1994). «Significación histórica de La Rétine des Vertébrés de Santiago Ramón y Cajal: Síntesis de su primera etapa investigadora». Asclepio. 46, 243-259. 
CONSOLIDACIÓN DE LA CARRERA INVESTIGADORA Y ACADÉMICA DE CAJAL EN LA ÚLTIMA DÉCADA DEL SIGLO XIX Y PRIMERA DEL SIGLO XX.

Estos trabajos fueron realizados por Cajal primero en Valencia y, en segunda instancia, en Barcelona, donde se trasladó como catedrático de Histología y Anatomía Patológica de la Universidad. En 1892, con un sólido prestigio internacional, Cajal obtuvo la cátedra de Histología de la Universidad de Madrid. Este paso significaba entonces la culminación de una carrera académica y el acceso a un ambiente científico que, a pesar de su pobreza y modestia, era más variado que el anterior. A su llegada a Madrid, se acometió una profunda remodelación de los laboratorios de la Facultad:

«Yo debo agradecerle [a Julián Calleja] la construcción y organización del Laboratorio de Micrografía, uno de los mejores y, por descontado, el más capaz e importante de San Carlos. La creación de este centro de estudio era apremiante, porque a mi llegada a la Corte encontremé por todo Laboratorio con cierto pasillo angosto y largo, pobrísimo de material e instrumental, sin libros ni biblioteca de Revistas. Quimérico resultaba dar, en tal angosto local, mediana enseñanza práctica a más de doscientos alumnos oficiales, amén de los libres.

Requerido por mí, D. Julian tomó sobre sí la reforma, gestionándola con extraordinario interés. Y haciendo gala de su maravillosa actividad, consiguió en pocos meses la consignación en presupuesto de los créditos necesarios y la ejecución de la obra. El nuevo Laboratorio de Histología, capaz para trescientos alumnos, se eleva frontero a la calle de Santa Isabel, encima de la grandiosa sala de disección: encierra gabinete de trabajo para profesores y ayudantes, gran salón de prácticas para los alumnos, departamentos de Bacteriología, de Microfotografía, etc.

Conseguido el local, siguiéronse los naturales complementos: la compra de libros y Revistas, adquisición de estufas de esterilización y vegetación, así como de número suficiente de microscopios. Al viejo e imponente Ross, el cañón del Laboratorio, menguadamente acompañado de un par de antiguos modelos de Verick y Nachet, añadieronse, en épocas sucesivas, dos magníficos Zeiss y 40 microscopios y microtomos de Reichert, destinados a los alumnos $»^{8}$.

Su llegada a Madrid le permitió, además, vincularse a la Sociedad Española de Historia Natural, sociedad científica creada en 1871 y editora de una prestigiosa revista, los Anales, en la que Cajal fue asiduo colaborador entre 1892 y 1896. Los trabajos editados en esta publicación tuvieron una relevancia internacional considerable y fueron traducidos al francés y alemán, lo que

8 Véase: RAMÓN Y CAJAL (1917), p. 220-221. 
facilitó su difusión ${ }^{9}$. En resumen, el traslado a la universidad madrileña conllevó una mejora sustancial en la infraestructura científica disponible (tanto de laboratorio, como de medios de comunicación científica) y su inserción en un medio intelectual y científico más propicio.

Zénit en la mejora en las condiciones de trabajo cajalianas en la última década del siglo XIX fue la aparición de la Revista Trimestral Micrográfica, publicación periódica, editada bajo la cabecera del «Laboratorio histológico de la Facultad de Medicina», en la que - por fin-Cajal dispondría de un medio especializado en el que dar a conocer sus propias investigaciones ${ }^{10}$.

En estos años la presencia de Cajal en los medios políticos, sociales y científicos fue creciente; creciente fue también su prestigio como investigador y profesor laborioso. Tuvo voz propia en la 'encuesta' que Joaquín Costa (1846-1911) elaboró para el Ateneo de Madrid y que fue publicada bajo el título Oligarquía y caciquismo como la forma actual de Gobierno en España: Urgencia y modo de cambiarla ${ }^{11}$; en ella, Cajal se presentará como un reformista moderado. En otros foros, de carácter más académico, Cajal se pronunció a favor de reformas graduales, de mejoras en la dotación y formación de jóvenes investigadores ${ }^{12}$; independientemente del éxito de estas propuestas - escaso, prácticamente nulo-, tiene interés destacarlas aquí ya que muestran a un hombre de ciencia consciente - y preocupado - por el desarrollo de la actividad científica en el seno de la sociedad española.

Pero es especialmente reseñable que, frente a otras grandes figuras del 'regeneracionismo', que se quedaron en un conjunto de exhortaciones retóricas a la reforma nacional, Cajal dio un paso más al asumir la creación y dirección de alguna institución de investigación que habría de tener un papel principal en ese proceso de regeneración: en 1899, ante un brote de peste en Portugal, se fundó el Instituto de Sueroterapia, Vacunación y Bacteriología Alfonso XIII (posteriormente Instituto Nacional de Higiene Alfonso XIII); una vez pasada la primera alarma por la infección, el Instituto se erigiría en elemento clave en la

9 Véase: Baratas DíAz, A.; Fernández Ruiz, B. (1999), «Santiago Ramón y Cajal y sus discípulos en la Real Sociedad Española de Historia Natural», Memorias de la Real Sociedad Española de Historia Natural, 2.

10 Véase: Timoner SAmpol, G. (2006), La Revista Trimestral de Micrografía y la Doctrina de la Neurona, Zaragoza, Institución Fernando el Católico.

11 Véase: Costa, J. (1982), Oligarquía y caciquismo como la forma actual de gobierno en España. Urgencia y modo de cambiarla, Zaragoza, Guara Editorial.

12 Véase: RAMÓN Y CAJAL, S. (1987), Apuntes para un plan de reforma de la enseñanza de las Facultades de Medicina. En: Ramón y Cajal. 1852-1934. Expedientes Administrativos de grandes españoles, Madrid, Ministerio de Educación y Ciencia. 
producción de sueros, las campañas de vacunación y la investigación sanitaria en las primeras décadas del siglo ${ }^{13}$.

Al comenzar el siglo XX, Cajal fue receptor de diversos galardones internacionales. En 1900 le fue concedido el Premio del Congreso Internacional de Medicina (conocido como premio Moscú); al aluvión de felicitaciones y notas de prensa se sumaron rápidamente las protestas por las condiciones materiales en las que el investigador desarrollaba su trabajo. En un ambiente oficial propicio a la reforma educativa y científica, el gobierno decidió establecer una partida presupuestaria -80.000 pesetas anuales - «para gastos de revistas, instrumental y material, y alquiler de su laboratorio biológico». Nació así el Laboratorio de Investigaciones Biológicas, que finalmente se instaló en un lateral del Museo Velasco, hoy Museo Nacional de Antropología en Atocha (Madrid) ${ }^{14}$.

«Excusado es decir — diría Cajal en su Autobiografía - que la creación del referido Laboratorio satisfizo plenamente mis aspiraciones. Sobre proporcionarme instrumental copioso y modernísimo, hizo desaparecer el déficit, que /.../ me ocasionaban la compra de libros y Archivos científicos, y sobre todo la publicación de mi Revista trimestral, de que vino a ser continuación el nuevo Anuario titulado Trabajos del Laboratorio de Investigaciones Biológicas. Excelente papel, grabados y litografías sin tasa, extensión ilimitada del texto en proporción con el original disponible, fueron las ganancias materiales logradas; y como provechos docentes la colaboración de cada día más intensa y reiterada de mis ayudantes y discípulos» ${ }^{15}$.

Posteriormente, la concesión del Premio Nobel de Medicina en 1906 confirió a Cajal un prestigio y reconocimiento social sin parangón; cuando en 1907, mediante un Decreto del Ministerio de Instrucción Pública se estableciese la Junta para Ampliación de Estudios e Investigaciones Científicas como organismo encargado de la formación de investigadores y la gestión de laboratorios, Cajal sería nombrado Presidente de la misma.

13 Véase: Porras Gallo, Ma I. (1998), «Antecedentes y creación del Instituto de Sueroterapia, Vacunación y Bacteriología de Alfonso XIII», Dynamis, 18, 81-105, y LEBRERO MENENDEZ, L. (1984). El Instituto Nacional de Higiene Alfonso XIII, Madrid, Universidad Complutense, (Tesis de Licenciatura inédita).

14 Véase: GonZÁlez de PABlo, Á. (1998), «El Noventayocho y las nuevas instituciones científicas. La creación del Laboratorio de Investigaciones Biológicas», Dynamis. 18, 51-79.

15 Véase: RAMÓN Y CAJAL (1917), p. 401-402. 
LUIS SIMARRO. UNA APROXIMACIÓN CLÍNICA E HISTOPATOLÓGICA A LA NEUROCIENCIA EN EL TRÁNSITO DEL SIGLO XIX AL XX.

Paralelamente a la figura de Cajal — máximo exponente de la investigación neurobiológica de carácter histológico-, en el panorama científico español de finales del siglo XIX había médicos e investigadores cuyo enfoque estaba orientado a otras vertientes. El caso más significativo es el de Luis Simarro. Tras iniciar medicina en la Universidad de Valencia, su activa participación política en los años del Sexenio le obligaron a finalizar sus estudios en la universidad madrileña. En la capital trabajó en el laboratorio micrográfico del Museo Antropológico de Velasco, enseñó en la Escuela Libre de Medicina y Cirugía que allí funcionaba y participó activamente en las sesiones de la Sociedad Histológica Española. En los primeros años de la Restauración formó parte del plantel docente de la Institución Libre de Enseñanza y trabajó en el Hospital de la Princesa y el Manicomio de Santa Isabel en Leganés, del que llegaría a ser director.

Entre 1880 y 1885 , coindiciendo con lo que algún autor ha llamado la 'diáspora institucionista', Simarro trabajó en París junto al histólogo Louis Antoine Ranvier (1835-1922), y los psiquiatras Jean Martin Charcot (18251893) y Valentin Magnan (1835-1916). Su formación internacional conjugaba las dos áreas de conocimiento que configurarían sus intereses científicos a lo largo de su carrera.

Pero la inserción en el escalafón universitario e investigador de Simarro fue tortuosa: tras su estancia parisina, a su regreso a Madrid, Simarro se consagró al ejercicio privado de la Neurología y la Psiquiatría. En esos años de la última década del siglo XIX, Simarro ejercerá puestos (secundarios) en instituciones oficiales y no oficiales: profesor de Psicología Fisiológica en el Museo Pedagógico Nacional, profesor en la Escuela de Estudios Superiores del Ateneo de Madrid; médico 'supernumerario' en el Hospital de la Princesa, etc. No sería hasta 1902, tras obtener la cátedra de Psicología Experimental en la Universidad de Madrid, cuando su trayectoria académica adquiera una cierta estabilidad; no obstante, la definitiva incorporación al profesorado oficial no impedirá a nuestro personaje continuar su incesante participación en iniciativas científicas, intelectuales e incluso políticas de todo tipo. En los primeros años del siglo XX Simarro continuó con el ejercicio clínico profesional, se embarcó en docencia psicológica en diversas facultades (Ciencias, Medicina, Filosofía), participó activamente en la creación de la Escuela de Criminología, mantuvo su laboratorio privado, fue activo miembro de la Real Sociedad Española de Historia Natural y agente promotor de la creación de la 
Asociación Española para el Progreso de las Ciencias, participó en la Junta para la Ampliación de Estudios, etc. ${ }^{16}$

Este brevísimo esbozo biográfico de Simarro nos muestra un personaje con intereses definidos en Neurociencia, con un enfoque poliédrico, más amplio que el de Cajal (entendido éste como un científico especializado, que sigue el surco de un área concreta de investigación), pero al tiempo menos eficaz en la obtención de resultados concretos y tangibles.

Cuando en 1907 se creó la Junta para Ampliación de Estudios su objetivo era formar investigadores y recoger en una superestructura los laboratorios e institutos de investigación ya existentes. La Junta fue muy eficaz en incorporar a su seno a aquellas personas o instituciones que realizaban trabajo científico y optimizar los recursos puestos a su disposición; como hemos apuntado en los párrafos precedentes, las dos grandes figuras de las neurociencias españolas en el primer tercio del siglo XX, Ramón y Cajal y Simarro, fueron los ejes sobre los que la Junta edificaría su política científica relativa a Neurociencias.

LOS DISCÍPULOS DE SIMARRO.

Nicolás Achúcarro y Pío del Río Hortega: el Laboratorio de Histología

Simarro fue un hombre con un amplio rango de intereses científicos e intelectuales, y multitud de testimonios avalan su capacidad como maestro y una gran generosidad para atraer hacia sí e iniciar en la Histología y Neuropsiquiatría a jóvenes brillantes, a los que abría de par en par el laboratorio doméstico, que compartía con Juan Madinaveitia (1861-1938), en su casa madrileña de General Oraá. El primero de los discípulos formado bajo su protección fue Nicolás Achúcarro Lund (1880-1918) ${ }^{17}$. Hijo de una familia de la alta burguesía bilbaína, Achúcarro completó su formación media en Alemania, tras lo que comenzó estudios de Medicina en la Universidad de Madrid; pero su carrera no fue lineal y realizó algunos cursos en la Facultad de

16 Véase: SimARro (2003). Luis Simarro y la psicología científica en España. Valencia, Universitat de València; Vidal Parellada, A. (1987). Luis Simarro y su tiempo. Madrid, CSIC, y el volumen colectivo «Los orígenes de la Psicología científica en España: el Doctor Simarro», Investigaciones psicológicas. 1987, 4.

17 La biografía más completa de Achúcarro es: Vitoria ORTIZ, M. (1977), Vida y obra de Nicolás Achúcarro. Bilbao, Editorial La Gran Enciclopedia Vasca. 
Medicina de Marburg (Hesse), antes de licenciarse en Madrid - como alumno libre- en 1904. Antes de finalizar sus estudios universitarios Achúcarro ya había mostrado gran querencia al laboratorio:

«Desde el año 1900 hasta terminar los estudios académicos de Medicina ha asistido y trabajado en el Laboratorio biológico de los Dres. Simarro y Madinaveitia, en asuntos de histología del sistema nervioso, dirigido por el Prof. Simarro» ${ }^{18}$.

Una vez titulado Achúcarro desarrolló su particular grand tour entre septiembre de 1905 y agosto de 1906, ampliando estudios sobre clínica y anatomía patológica de las enfermedades nerviosas en el hospicio de Bicètre - en París-, trabajando en la clínica psiquiátrica de San Salvi, de Florencia, y, finalmente, realizando una estancia en la clínica psiquiátrica de Múnich, donde asistió al curso de psiquiatría de Emil Kraepelin (1856-1926) y «comencé un trabajo experimental en el laboratorio anatomopatológico de la Clínica dirigido por el profesor Alzheimer» ${ }^{19}$.

En 1907 figura en la nómina de solicitantes de beca ante en la primera convocatoria que emitió la Junta para Ampliación de Estudios. En su petición Achúcarro indicaba que pretendía ocuparse durante un año de estudios sobre "clínica psiquiátrica y en investigaciones personales sobre Anatomía patológica de las enfermedades mentales en París y varios puntos de Inglaterra». Razonaba su preferencia por las clínicas francesas - frente a las alemanaspor la mayor facilidad para obtener material humano de estudio y las menores trabas burocráticas a los investigadores extranjeros, para terminar resumiendo - magníficamente - sus intereses de investigación:

«Nosotros (después de haber estudiado en este medio [las clínicas alemanas] por espacio de un año) pretendemos seguir estudiando la psiquiatría y su anatomía patológica sin excluir del todo de nuestros estudios las enfermedades llamadas somáticas del Sistema Nervioso, utilizando el gran material de Bicètre y la dirección de nuestro maestro Pierre Marie y hacer después de este periodo un viaje de 3 o 4 meses en Inglaterra con el fin de conocer la organización psiquiatrica de aquel país, de estudiar algunos puntos de fisiología cerebral y de trabajar muy especialmente en un centro de anatomía patológica que por circunstancias especiales de relación colonial ha sido estudiado en Inglaterra por Mott (nos referimos a la enfermedad del sueño) $»^{20}$.

18 Solicitud de pensión de Nicolás Achúcarro, 9 de agosto de 1907. Expediente Achúcarro. Archivo de la Junta para la Ampliación de Estudios, Residencia de Estudiantes.

19 Ibídem.

20 Ibídem. 
No tenemos constancia de que la pensión fuera concedida, no obstante un nuevo y provechoso acontecimiento se cruzó en la vida de Achúcarro. Según relata Gonzalo Rodríguez Lafora (1886-1971) ${ }^{21}$, estando Achúcarro en Múnich - de nuevo en la Clínica de Kraepelin - visitó el centro un médico norteamericano comisionado por su gobierno para contratar un especialista en patología para el Goverment Hospital for the Insane de Washington; por consejo de Alzheimer (1864-1915) el puesto le fue ofrecido al médico español. Achúcarro permaneció en Estados Unidos entre 1908 y 1910, meses en los que organizó el laboratorio de histopatología del centro, instruyó en técnicas histológicas al personal y fue colaborador en la revista científica del hospital. En su nota de recuerdo, Rodríguez Lafora hacía amplia referencia a un trabajo de Achúcarro sobre «El estado actual de la histopatología en el estudio de las enfermedades mentales», en el que se mostraba defensor de los logros histopatológicos y las nacientes técnicas histoquímicas; apuntaba —además- las líneas de trabajo que serían importantes en años venideros dentro de su labor científica: las funciones metabólicas y endocrinas de la neuroglía y la glioarquitectura $^{22}$.

Achúcarro regresó definitivamente a España en 1910, pero los primeros meses de reincorporación a nuestro tejido científico fueron duros: recién casado, sin un puesto de investigación estable, se verá abocado a la práctica clínica y a completar sus ingresos con el ejercicio privado; los sucesivos esfuerzos para dotarle de un cargo oficial - algunos de ellos promovidos por Cajal - no cristalizaban. La situación parecía crítica, Vitoria Ortiz menciona una nota de Achúcarro que trasluce una cierta amargura y parece preludiar el abandono de la investigación: «El poco éxito de las cosas oficiales del laboratorio y del hospital me tiene algo disgustado, y casi estoy pensando en dejar lo del laboratorio de Cajal, que me quita tiempo y de lo que por lo visto no voy a sacar nada. Me parece que me voy a dedicar por entero a las cosas de la clínica y si alguna vez gano lo suficiente, entonces volveré a las cosas de la experimentación; una ilusión que naturalmente me cuesta abandonar para siempre» ${ }^{23}$.

Afortunadamente la Junta para Ampliación de Estudios supuso un 'salvavidas' para la actividad investigadora de Achúcarro. En 1910 se estableció la

21 Véase: Rodríguez LAforA, G. (1968), «Mis recuerdo de Nicolás Achúcarro». En MoyA, G. (Ed). Nicolás Achúcarro (1880-1918) su vida y su obra. Madrid, Taurus Ediciones, p. 97-98.

\footnotetext{
22 Ibídem.

23 Vitoria Ortiz, M. (1977), p. 150.
} 
Residencia de Estudiantes, que además de alojamiento tenía como misión ofrecer cursos, conferencias y actividades formativas para los jóvenes universitarios madrileños. En el curso 1912-1913 se impartió por vez primera un curso práctico de Histología, dirigido por Achúcarro, que sería el embrión del Laboratorio de Histología, cuya dirección asumió Achúcarro. Tras una corta estancia en la Residencia, en la que se formó un pequeño grupo de alumnos colaboradores, el Laboratorio se trasladó al 'Museo Velasco', donde compartió espacio con el Laboratorio de Investigaciones Biológicas de Cajal. Eran, formalmente, instituciones científicas distintas, pero tenían temáticas y métodos comunes y el material era utilizado indistintamente. Veremos más adelante como, una vez desaparecido Achúcarro, esta convivencia se fue agriando y se saldó con una separación traumática; pero de momento enfaticemos que la creación del Laboratorio de Histología permitió a Achúcarro su integración 'oficial' en el sistema científico español y que la Junta se mostró ágil para estabilizar la situación profesional de un notabilísimo investigador con una trayectoria y reconocimiento internacional importante.

Desgraciadamente en 1916 Achúcarro empezó a mostrar los primeros síntomas de una enfermedad degenerativa (conocida como enfermedad de Hodgkin) que dificultó, primero, y finalmente, impidió totalmente, su actividad científica. El deterioro físico fue lento y doloroso y nos privó de un investigador de primer orden en el momento de su mejor producción científica y de la cristalización definitiva de su tarea docente. Tras dos años de lucha con la enfermedad Achúcarro falleció en abril de 1918.

Afortunadamente, la desaparición de Achúcarro no determinó la extinción del Laboratorio: la dirección del centro se encomendó a Pío del Río Hortega (1882-1945). Licenciado en Medicina en la Universidad de Valladolid e introducido en la Histología por Leopoldo López García (1854-1932), catedrático allí y discípulo de Aureliano Maestre. En los últimos meses de 1913, gracias a una beca del Instituto del Cáncer amplió sus estudios sobre histología, bacteriología y oncología en París, Berlín y Londres ${ }^{24}$. A su regreso (marzo de 1916) se incorporó al Laboratorio de Histología dirigido por Achúcarro; éste le induce a continuar en el centro y a no desvincularse de la investigación (más tarde sabría que parte de su gratificación se detraía de la del

24 Esta beca obtuvo la ‘equiparación' de pensión de la Junta para Ampliación de Estudios (Memoria de la Junta para Ampliación de Estudios correspondiente a 1914-1915, pág. 121). Este procedimiento de 'equiparación' confería al becado el mismo estatus que los becarios de la Junta por más que sus emolumentos los pagase otro organismo; era un procedimiento para 'convalidar' los estudios internacionales realizados por investigadores españoles. 
propio Achúcarro). Río, trabajador tenaz, adquirió una presencia y protagonismo creciente en el Laboratorio, que se acentuó con la enfermedad y fallecimiento de su maestro. En 1918 se encargó oficialmente de la dirección del Laboratorio de Histología y, en un tiempo relativamente breve, la armonía que regía las relaciones entre el Laboratorio cajaliano y el de Histología, se rompió tras una serie de desagradables incidentes que se saldaron (octubre de 1920) con la expulsión de Río del laboratorio cajaliano y la instalación del Laboratorio de Histología en la Residencia de Estudiantes ${ }^{25}$. El 'nuevo' centro recibirá en primera instancia el nombre de Laboratorio de Histopatología del Sistema Nervioso, que fue cambiado posteriormente por el de Laboratorio de Histología Normal y Patológica.

Los años en que el Laboratorio de Histología convivió con el de Investigaciones Biológicas en el caserón del Museo Antropológico y posteriormente durante su asiento en la Residencia de Estudiantes fueron - a pesar de las dificultades - los más provechosos para Río Hortega. En 1920 dio a la imprenta la descripción de un método histológico nuevo (basado en el uso de carbonato argéntico) y al año siguiente describió un nuevo elemento celular del tejido nervioso, al que denominó microglía, caracterizando su origen embrionario y su significado funcional; ese mismo año de 1921 describió un cuarto tipo celular, al que llamó oligodendroglía, y de nuevo aclaró su histogénesis y función ${ }^{26}$.

En esos años, las Memorias de la Junta para Ampliación de Estudios muestran como el laboratorio de Río en la Residencia era un hervidero de colaboradores, muchos de ellos procedentes de repúblicas iberoamericanas $\mathrm{y}$, alguno que otro, del ámbito anglosajón: uno de estos últimos fue Wilder Penfield (1891-1976). Por consejo del fisiólogo británico Charles S. Sherrington (18571952), colega y admirador de Cajal, Penfield viajó a Madrid para adiestrarse en la técnica micrográfica utilizada en España. Trabó contacto con el Laboratorio de Histología Normal y Patológica y valoró así los conocimientos que adquirió aquí: «With the anatomical skills I had learned in Madrid, I could now make my own fundamental scientific approach to problems in neurosurgery. And I longed to apply it to the whole field of clinical neurology» 27 .

25 El relato de Río Hortega respecto del desencuentro con Cajal está disponible en: Río Hortega, P. (1986). El Maestro y yo. Madrid, CSIC.

26 Cano Díaz, P. (1985). Una contribución a la Ciencia Histológica: La obra de Don Pío del Rio-Hortega. Madrid, CSIC - Instituto «Arnau de Vilanova».

27 ECCles, J.; FeIndel, W. (1978). «Wilder Graves Penfield». Biographical Memoirs of Fellows of the Royal Society. 24, 476-477. 
Los puestos de investigación en los laboratorios de la Junta eran gratificados de forma modesta. Ya vimos como Achúcarro pasó apuros económicos hasta su total estabilización profesional y como compatibilizó actividades en diversos centros públicos y privados. El mismo esquema se repite en el caso de Río Hortega. A partir de 1928, compatibilizó el trabajo en el Laboratorio de Histología, con un puesto en el Laboratorio de Cancerología Experimental del Instituto Nacional de Oncología (recordemos que le unía a esta institución una larga relación desde que había sido becario de la misma); adicionalmente en 1929 fue designado Director Honorario del Laboratorio de Anatomía Patológica y Cancerología de la Casa de Salud Valdecilla de Santander, haciéndose cargo de un curso de tres meses en el verano. Esta consolidación profesional inclinó el grueso de su actividad científica hacia la investigación oncológica del sistema nervioso. Durante los años de la II República Río Hortega tomo progresivamente mayor responsabilidad científica y académica en el Instituto del Cáncer, del que sería Director a partir de 1932. El estallido de la Guerra Civil le obligó al exilio, primero en París, después en Oxford y finalmente en Argentina, país con el que había tenido estrecha relación científica previa.

Independientemente de la evolución científica del Laboratorio de Histología Normal y Patológica y de la trayectoria vital de sus directores, hay un factor fundamental para entender el papel de este tipo de centros en el esquema de la Junta. Estos laboratorios se concebían como instituciones (modestas) de investigación, pero fundamentalmente se entendían como focos de iniciación a la investigación. Por sus salas, primero bajo la dirección de Achúcarro y después bajo Río, pasaron una auténtica legión de jóvenes médicos: Luis Urtubey Rebollo, Manuel Pérez Lista, José Manuel Ortiz Picón, Antonio Llombart Rodríguez, Enrique Vázquez López y un largo etcétera adquirieron su formación histopatológica en este centro y de allí fueron saliendo para ocupar plaza en servicios de anatomopatología por todo el país ${ }^{28}$.

\section{Isaac Costero y el laboratorio de Histología de Valladolid}

Mención especial merece entre los asiduos del Laboratorio de Histología la figura de Isaac Costero Tudanca (1903-1979), que ingresó en el Laboratorio en 1922 y disfrutó de sendas becas de la Junta en centros alemanes donde amplió sus estudios sobre cáncer y la novedosa técnica — entonces- de cul-

28 Véase: Oliva Aldamiz, H. (1984). Cajal y la anatomía patológica española, una historia compartida. Barcelona, Salvat Editores. 
tivos celulares. Aplicó esta técnica a uno de los objetos de estudio de su maestro, la microglía, dando a la imprenta - en el seno de la Sociedad Española de Historia Natural - una memoria titulada «Estudio del comportamiento de la microglía cultivada in vitro (Datos concernientes a su histogénesis) $\gg{ }^{29}$. Costero ganó por oposición la cátedra de Anatomía Patológica de la Universidad de Valladolid en 1931, e incorporado a la ciudad castellana se convirtió en un factor de renovación científica: con apoyo de la Fundación Nacional para investigaciones científicas y ensayos de reforma, una institución creada por el gobierno republicano para fomentar la investigación básica y aplicada y que pretendía superar la tradicional focalización de centros de investigación en Madrid, se estableció —en 1934- el Laboratorio de Histología y Cultivo de Tejidos.

Costero repitió en su laboratorio vallisoletano el mismo esquema que su maestro en Madrid y rápidamente empezó a contar con discípulos y colaboradores como Rafael Criado Amunátegui (que sería después patólogo en la Universidad de Puerto Rico), Enrique Merino Eugercios (después catedrático en Venezuela), Francisco López Suárez o Vicente Jabonero.

Estrechamente vinculado a la vida corporativa de la Universidad (colaboró en la celebración de sesiones de cine científico, propició conferencias de profesores internacionales, fue Secretario Académico de la Facultad, etc.). El estallido de la Guerra Civil le sorprendió en Santander, en zona leal a la República, haciendo las amenazas imposible su regreso a Valladolid. Inició así un largo exilio que le conduciría a París, primero, y después a México donde desarrolló una notable tarea investigadora y docente ${ }^{30}$.

\section{Gonzalo Rodríguez Lafora y el Laboratorio de Fisiología Cerebral.}

Gonzalo Rodríguez Lafora estudió medicina en la Universidad de Madrid, donde trabó contacto con Juan Madinaveitia y Luis Simarro, siendo asiduo en el laboratorio que ambos compartían. Al completar su licenciatura (en 1907) tenía ya una sólida formación histológica obtenida junto a Simarro y había

29 Costero, I. (1930). «Estudio del comportamiento de la microglía cultivada in vitro (Datos concernientes a su histogénesis)». Memorias de la Real Sociedad Española de Historia Natural. 14, 123-182.

30 Véase: LóPez De LetonA, C. (1995). Vida y obra del Profesor Isaac Costero Tudanca. Valladolid, Secretariado de Publicaciones. Universidad de Valladolid. (Acta histórico-médica vallisoletana. Monografías, $n^{\circ} 44$ ). 
colaborado esporádicamente en el Laboratorio de Investigaciones Biológicas de Cajal. En agosto de 1907 - significativamente en los mismos días que Nicolás Achúcarro - solicitó ante la Junta una beca, para "hacer un estudio superior de la especialidad Enfermedades del sistema nervioso con inclusión de las mentales» ${ }^{31}$; su pretensión era estudiar Histología del Sistema Nervioso junto a Nissl, anatomía patológica con Alzheimer y Psiquiatría con Emil Kraepelin. La beca le fue concedida, pero los centros y profesores de destino cambiaron ligeramente: la Memoria de la Junta correspondiente a 1910-1911, confirma la pensión concedida en 1908 y la estancia en Berlín, junto a Oskar Vogt (1870-1959), con quién estudió anatomía del sistema nervioso y con Theodor Ziehen (1862-1950) con quién estudió anatomía patológica; en Múnich trabajó junto a Kraepelin y Alzheimer, dedicándose a la histopatología de las enfermedades mentales. En 1909 Lafora obtuvo una nueva beca de la Junta, en este caso para "hacer estudios de Fisiología cerebral y anatomía patológica del sistema nervioso en Inglaterra, París y Roma»; a esta pensión renunció en mayo de 1910, fecha en que sustituyó a Achúcarro en el departamento patológico del manicomio federal de Washington.

A regreso de su etapa norteamericana (1912), Lafora se vio obligado a aceptar puestos secundarios (auxilar interino de psicología en la cátedra de Medicina Legal), que compatibilizó con la práctica clínica y el ejercicio privado. Son - al igual que para Achúcarro - meses difíciles, de trabajos múltiples que muestran una gran capacidad de adaptación y un amplio rango de intereses científicos, pero también una dificultad objetiva de reincorporación en el tejido científico español.

Finalmente, en 1916 la Junta estableció el Laboratorio de Fisiología Cerebral cuya dirección se encomendó a Lafora. El Laboratorio encontró acomodo en las plantas altas de Museo Velasco, compartiendo espacio con el laboratorio cajaliano. Lafora recordaba así el Laboratorio:

«por gesto admirable del maestro Cajal, dirigía yo desde hacía años en la buhardilla del viejo Instituto Cajal en el Paseo de Atocha. Allí subía algunas veces D. Santiago, en ocasiones acompañado por Tello, para animarnos con sus consejos y comprobar las intervenciones operatorias que realizábamos en monos, perros y gatos (previamente amaestrados según la técnica de Kalischer en la ejecución de ciertos ejercicios dentro de jaulas especiales ideadas por nosotros), para poder estudiar después clínicamente los síntomas consecutivos a las lesiones producidas en diversos centros nerviosos, y luego, tras algunos meses, comprobar la localización de las lesiones

31 Solicitud de beca de Gonzalo Rodríguez Lafora, fechada el 8 de agosto. Expediente de Rodríguez Lafora. Archivo de la Junta para Ampliación de Estudios, Residencia de Estudiantes. 
en los cortes en serie del cerebro, cerebelo y tronco cerebral. Allí, entre 1915 y 1936, nos ayudaron y colaboraron con nosotros los colegas Prados, Germain, Aydillo, alguna vez de Castro, Sanz Ibáñez, Álamos, y por breve tiempo algunos otros. Los diversos trabajos sobre la función del cuerpo calloso, las enfermedades del movimiento originadas por lesiones en los núcleos grises de la base, el sueño experimental, las funciones tróficas del diencéfalo, etcétera, que publicamos en colaboración con algunos de ellos, motivaron también comunicaciones nuestras a diversos Congresos Internacionales de Fisiología, de Neurología y de Psicología, como los de París (1921), Berna (1931), Groningen (1934) y Londres (1935)» $\rangle^{32}$.

Algún biógrafo, quizá demasiado taxativamente, considera que la denominación del Laboratorio como de Fisiología Cerebral era debida a razones de carácter administrativo, ya que su verdadero objeto de estudio sería la histopatología ${ }^{33}$. Lafora, cuya primera formación fue como histopatólogo y psiquiatra, realizó un esfuerzo considerable por abordar experimentos e investigaciones de carácter fisiológico - en ocasiones con un fuerte componente anatomopatológico-; de esta forma realizó trabajos sobre la localización de centros cerebrales involucrados en movimientos involuntarios, los efectos funcionales de tumores y quistes, la circulación del líquido cefaloraquídeo, etc. Este conjunto de trabajos, cuantitativamente poco importante, adquieren importancia si se enmarcan en la evolución de la obra científica de Lafora: los estudios fisiológicos suponen el punto de inflexión entre una etapa en la que predomina el enfoque histopatológico a otra en el que domina la dimensión neuropsiquiátrica ${ }^{34}$.

\section{El LABORATORIO DE INVESTIGACIONES BIOLÓGICAS BAJO LA JUNTA}

Cuando en 1907 se estableció la Junta para Ampliación de Estudios, el Laboratorio de Investigaciones Biológicas se integró en ella. La constitución del Laboratorio fue una mejora importante en la carrera científica de Cajal, en primer lugar le permitió disponer de una infraestructura material para su trabajo que - a pesar de su modestia - superaba todo lo anterior, por otro lado significó una considerable mejora en la edición de sus resultados científicos.

32 Cfr. Rodríguez Lafora, G. (1959). «En Memoria del Profesor Francisco Tello». Revista IBYS. 17 (2), 201.

33 Véase: Valenciano Gaya, L. (1977). El Doctor Lafora y su época. Madrid, Ediciones Morata, p. 197.

34 Véase: González CAjal, J. (1984). Estudio de la obra científica del Profesor Doctor D. Gonzalo Rodríguez Lafora. Salamanca, Universidad de Salamanca, p. 32-35. 
Pero hay otros dos aspectos en los que la existencia del Laboratorio supone un cambio trascendental en la obra cajaliana. En primer lugar, le permitió abordar un problema de carácter experimental que hubiera sido imposible de estudiar en el marco de un laboratorio doméstico o en el laboratorio de la Facultad, lógicamente más orientado a la docencia que a la investigación. Entre 1905 y 1914 Cajal realizó un portentoso trabajo sobre la regeneración y degeneración de los nervios, que le permitió demostrar — otra vez- la independencia de las células nerviosas, describir los procesos de neurogénesis y neurodegeneración y plantear innovadoras hipótesis sobre el 'factor neurotrópico', la sustancia que estimularía el crecimiento de las prolongaciones nerviosas ${ }^{35}$.

El otro aspecto a considerar es cómo el Laboratorio le permitió disponer de un marco de trabajo para colaboradores y discípulos. La nómina de colaboradores que se recogen en las Memorias de la Junta es larguísima; en las siguientes líneas citaremos sólo a las figuras más relevantes.

En 1902 se incorporó al Laboratorio Jorge Francisco Tello, que había de ser el discípulo más estrecho de Cajal durante más de treinta años. Tello secundó a su maestro en diversos puestos subalternos en el Laboratorio, el Instituto de Higiene y la cátedra universitaria. En 1911 Tello fue becado por la Junta para ampliar sus conocimientos sobre anatomía patológica y enfermedades infecciosas en Berlín; a su vuelta a España, siempre a la sombra de su maestro, fue responsable de la renovación de la enseñanza de la anatomía patológica en la facultad madrileña y desarrolló una importante labor organizando el servicio de autopsias del Hospital de San Carlos $^{36}$.

En los últimos años de la década de 1910 y en los primeros años de 1920 se vincularon al laboratorio Fernando de Castro y Rafael Lorente de No. De Castro se incorporó al Laboratorio de Cajal siendo todavía estudiante, y cuando acabó su licenciatura en 1921 era ya un investigador con proyección. En los primeros años de la década de 1920 fue nombrado, sucesivamente, ayudante de clases prácticas de la facultad, becario de la Junta y responsable de becarios en el laboratorio cajaliano; en 1925 obtuvo plaza como profesor auxiliar de la cátedra de Histología y en 1929 una ayudantía en el Instituto

35 Véase: Baratas DíAz, A. (1997), «La obra neuro-embriológica de Santiago Ramón y Cajal», Dynamis, 17, 259-279.

36 Véase: Collazo Rodríguez, A. F. (1981). Vida y obra de Jorge Francisco Tello. Madrid, Editorial de la Universidad Complutense.

CASTRO, F. (1981). «Tello, discípulo de Cajal». En: Cajal y la Escuela Neurológica española. Madrid, Editorial de la Universidad Complutense, pp. 108-121. 
Cajal. La estabilización profesional definitiva le llegó en 1933 cuando obtuvo la cátedra de Histología y Anatomía Patológica de Sevilla; no obstante, tras tomar posesión de ella, solicitó la excedencia y se incorporó con su antigua categoría al Instituto Cajal. El estallido de la Guerra Civil afectó profundamente la trayectoria científica de De Castro, que decidió quedarse en Madrid y permaneció en la ciudad durante la contienda; tras ella tuvo que hacer frente a no pocos problemas económicos e institucionales ${ }^{37}$.

Rafael Lorente de No fue el más joven de todos los discípulos directos de Cajal. Por consejo de Pedro Ramón (hermano de Santiago) se trasladó a Madrid, para finalizar sus estudios en Medicina e incorporarse al Laboratorio de Investigaciones Biológicas. Becado por la Junta para Ampliación de Estudios en 1924, realizó largas estancias en laboratorios del norte de Europa: trabajó en Upsala, junto a Robert Bárány (1876-1936), premio Nobel en 1914, y en Berlín, junto a Oskar y Cecile Vogt. A su vuelta a España, en 1927, Lorente no pudo obtener un puesto de investigación en el Instituto Cajal y fue nombrado director del servicio de Otorrinolaringología del Hospital Valdecilla, de Santander. Con una formación científica sólida, pero con enormes dificultades institucionales para desarrollar trabajo de investigación, terminó aceptando - en 1931 - la invitación del Central Institute for the Deaf, de San Luis (Missouri), donde prosiguió una carrera investigadora que se construiría ya al margen de la realidad científica española ${ }^{38}$.

\section{CONCLUSIONES}

Las Neurociencias en la España del primer tercio del siglo XX alcanzaron un nivel de excelencia sin igual en nuestra historia científica. La gran obra de Cajal se nos presenta como la cúspide científica de esta etapa, pero es necesario enfatizar la tarea de otros muchos investigadores cuyo trabajo no fue tan

37 Bullón RAmirez, A. (1981). «Biografía del profesor Fernando de Castro, catedrático de Histología de la Universidad Complutense». En: Cajal y la Escuela Neurológica española. Madrid, Editorial de la Universidad Complutense, pp. 133-180, y GALLEGO, A. (1981) «Fernando de Castro. (1896-1967)». En: Cajal y la Escuela Neurológica española. Madrid, Editorial de la Universidad Complutense, pp. 124-132.

38 Véase: Gallego FernáNDEZ, A. (1990). «La obra científica del doctor Lorente de No». Anales de la Real Academia Nacional de Medicina. 107 (3), 467-480. KRUGer, L.; Woolsey, T. A. (1990), «Rafael Lorente de Nó: 1902-1990». The Journal of Comparative Neurology. 300, 1-4. Woolsey, T. A. (2001). «Rafael Lorente de No». Biographical Memoirs of the National Academy of Science. 79, 84-105. 
notable, pero que en conjunto suponen un esfuerzo colectivo por la mejora del nivel científico y cultural. El análisis microscópico del tejido nervioso, la Neurohistología, fue la columna vertebral del desarrollo de las Neurociencias españolas. Todos los citados en estas páginas eran grandes microscopistas, dotados de técnicas histológicas afines (en las que las sales de plata eran la pieza clave); variaba, sí, el enfoque del estudio, mientras Cajal y sus discípulos más directos estudiaron el sistema nervioso 'normal', tanto en el hombre como en diversos grupos animales, Simarro y los suyos (Achúcarro, Rodríguez Lafora, Río Hortega) prestaron mayor atención a problemas patológicos y psiquiátricos.

La obra de Cajal se vio claramente favorecida por la Junta para Ampliación de Estudios: no sólo porque la Junta asumió los presupuestos de su laboratorio y publicaciones, también permitió la formación internacional de algunos de sus colaboradores más directos. En el caso de Achúcarro, Lafora y Río, que directa o indirectamente, estaban más vinculados a Simarro, la Junta amparó su formación científica internacional y, con algunas dificultades, estableció laboratorios en que les fue posible continuar su trabajo científico.

No obstante, la carrera científica de todos - y a pesar de la actitud favorable de la Junta - estuvo jalonada de preocupaciones y carencias. Las gratificaciones modestas impedían el desarrollo de una sola actividad y muchos de nuestros protagonistas debieron compatibilizar diversos empleos y comisiones de trabajo, que si bien ampliaban el rango de sus actividades - factor siempre positivo-, impedía la consolidación de una trayectoria científica sólida. Cuando algunos de ellos obtuvieron cátedras en universidades periféricas, no siempre conllevo la extensión de nuevos focos de investigación en neurociencias.

Si hay algún ejemplo de los desajustes en el desarrollo institucional de las Neurociencias en España, este es — sin duda - el establecimiento del Instituto Cajal y la construcción de un edificio para su sede. En 1920, mediante Real Decreto, se establecía el Instituto Cajal, que pretendía honrar la figura del investigador próximo a su jubilación. El Decreto establecía que se vincularían al nuevo instituto el Laboratorio de Investigaciones Biológicas, de Histología, Neuropatología, Fisiología, y todos aquellos que el propio Cajal considerase oportuno. Evidentemente el objetivo era constituir un gran centro de investigación biomédica, en el que las Neurociencias se constituían en columna vertebral de la actividad. Desgraciadamente este proyecto se fue desdibujando con el tiempo, el proceso de construcción del edificio estuvo plagado de errores, malos entendidos y mala planificación, por lo que el edificio no se pudo utilizar hasta bien entrados los años treinta, poco antes del fallecimiento de 
Cajal, que prácticamente no lo llegó a utilizar. Entre tanto, notables y prometedoras figuras - como Lorente de No- se vieron obligados a abandonar el país ante la falta de perspectivas institucionales para su investigación.

La 'Escuela Neurológica española' vertebrada en torno a Cajal en las primeras décadas del siglo XX realizó una tarea titánica, sentó los cimientos de la moderna neurociencia, poniendo a nuestro país en el mapa de la investigación científica de su época, en un área —además - absolutamente innovadora. Pero algunas disfunciones contrastan el balance enormemente positivo de este grupo: quizá faltó 'masa crítica', más investigadores, más profesores, una mejor organización científica, etc, para sacar hasta la última gota de rendimiento científico y académico a unas figuras imponentes. No obstante, todas estas son cuitas de historiador, el desarrollo de las Neurociencias españolas - de toda la ciencia y de toda la vida social e intelectual española - se vio atropellado en el verano de 1936. La ciencia y la sociedad que emergió tras aquél profundo terremoto sería ya algo irremisiblemente distinto. 